\title{
Relational Aggression between Primary School Girls
}

\author{
Jennifer Browne \\ Psychologist, Ministry of Education, Special Education (GSE), Epsom \\ Janis Carroll-Lind \\ Senior Lecturer, Massey University, Palmerston North
}

\begin{abstract}
This article presents the findings of a case study undertaken with the year 5 girls in one school to investigate their experiences and understanding of covert intimidation, as well as the effects and impact of these practices in the school setting. The findings of the study were obtained from the analysis of interviews, researcher-generated documents (worksheets) and surveys. They suggest that covert intimidation does exist in the school setting, and more particularly that these practices are an integral part of relationships between girls, through which they resolve the anger and conflict that arise in their friendships. These practices are located in the heart of girls' relationships and operate beneath the surface of ordinary school life. The conclusion of the study is that the term relational aggression should be used as a descriptor to help bring the phenomenon of covert aggression into the open. Open acknowledgment of these practices will help address these behaviours between girls so that they can learn open and honest ways of relating to each other, particularly in the resolution of their conflicts.
\end{abstract}

\section{Research paper \\ KEYWORDS}

Girls, aggressive behaviour, harassment, victimisation, social behaviour, bullying, peer relationships.

\section{INTRODUCTION}

The focus on bullying by schools over the last decade in New Zealand has primarily been concerned with overt acts of aggression that have mainly involved boys. In defining bullying, Olweus (1993) includes several key components. These are that negative actions are directed towards a person by one or more others, repeatedly over time, and there is an asymmetrical power relationship between two or more people. Aggression between girls, while taking more covert forms and involving social isolation and intentional exclusion from a group, meets the criteria set out by Olweus (Espelage, Mebane \& Swearer, 2004). The contrast between the two different forms of aggression is poignantly drawn by the following statement made by a teacher in this study, who said:

... by its very nature we can ignore it as long as we like, whereas we can't ignore someone going out and biffing someone in the playground. We have to do something about that.
Many New Zealand schools have implemented school-wide prevention programmes as a response to bullying in the school environment. These programmes include the Eliminating Violence - Managing Anger Programme, the No Blame Approach, Kia Kaha, and the Cool Schools Peer Mediation Programme. However, while acknowledging the existence of indirect practices such as intimidation or manipulation, many of these school-wide programmes have not specifically addressed the practices that are more commonly found between girls. Sullivan (2000) suggests that indirect bullying by girls possibly gets neglected because it takes subtle forms and there is little outward sign of harm. Other researchers assert that it is partly due to the perception that indirect bullying is not bullying in the true sense. Boulton and Hawker found in their UK study that only about half of teachers and junior pupils, and one fifth of secondary school pupils, considered 'deliberate social exclusion' to be bullying (Stanley \& Arora, 1998).

\section{THE PHENOMENON}

In the last decade, researchers have provided a series of definitions to describe the phenomenon of aggression or bullying of a non-physical nature. Crick and her colleagues describe "behaviours that harm others through damage (or the threat of damage) to relationships or feelings of acceptance, friendship or group inclusion' as relational aggression Crick et al., 1999, p.77). Galen and Underwood (1997) discuss social aggression as behaviours that damage another's self-esteem or social status, including non-verbal behaviours such as negative facial expressions or bodily movements, as well as more indirect forms such as slander and social exclusion. Dellasega and Adamshick (2005) simply define relational aggression as 'the use of relationships to hurt another' (p. 63). Simmons (2002, p.23) provides a hint about the dynamics involved when she notes that, "covert aggression isn't just about not getting caught; half of it is looking like you'd never mistreat someone in the first place.'

It has commonly been thought that these practices occur more frequently during secondary school years. However, teachers have expressed concern and have sought help from the researcher in her role as a Resource Teacher of Learning and Behaviour (RTLB) in five primary schools as a result of relational aggression through covert intimidation. This research study rose from the desire to more effectively 
support girls in our schools to develop the social skills and behaviours necessary to resolve difficulties in interactions.

The three aims of this qualitative case study were

1. to ascertain whether year 5 girls did in fact perceive themselves as experiencing covert intimidation from other girls.

2. to understand the meanings the girls gave to their experiences.

3. to explore the effects and impact of those experiences.

\section{THE METHOD}

This study aimed to investigate whether covert intimidation occurred among a group of 23 year 5 girls aged between nine and ten years who were drawn from four composite year 5 and 6 classes. The study sought to examine what the effects and impact of these practices were in the school setting, which in this case was a medium-sized, inner city, decile 7 , contributing state primary school.

The case study contained four data gathering techniques.

\section{Survey and worksheet}

The survey questionnaire and worksheet obtained information about the girls' experiences and understandings of covert intimidation (see Appendices 1 and 2). This information helped to check assumptions about the incidence of the practices and the girls' understandings, and provided more detailed information on which the remaining data gathering methods were based. The survey and worksheet not only provided information about a phenomenon that could not easily be observed, but they provided the girls with the opportunity to reflect more deeply on social interactions in the school setting. Completion of the survey and worksheet was able to be carried out privately and confidentially. Additionally, the writing, due to its reflective nature, empowered the girls to make more informed choices about the extent and kind of information they were willing to share in the group discussions.

\section{Semi-structured group discussions and semi-structured interviews}

A total of seven girls from one class, six from another and five girls from two others made up the five discussion groups, which had a membership of five or four girls in each. This membership was a tender topic for some students, with one student opting out of the discussion groups, so guiding the composition of the groups was the year 5 and 6 teachers' knowledge of the dynamics between the girls. Additionally, girls were able to make confidential requests for changes in the groupings through the class post boxes and several girls did this. Further supports were put in place to ensure that any distress experienced by the girls was addressed. These included the deputy principal and a counsellor making themselves available, post boxes being placed in all the classrooms and informing parents of the days that their daughter's discussion group would take place.
The discussions, which took place in a private room, were guided by the researcher, who used a semi-structured interview schedule to gain information about the girls understandings of practices of covert intimidation, as well as the effects and impact of those practices (see Appendix 3). The discussion groups, which were bound by structured group processes such as negotiated group rules, including confidentiality, provided the girls with the means to relate the reality of their social lives without the constraints of forming a written message.

The adults' perspectives of the phenomenon were gained through tape recorded, semi-structured interviews with the four year 5 and 6 teachers (see Appendix 4).

\section{TABLE 1}

Conceptual Framework Derived From Data Analysis

\begin{tabular}{|c|c|}
\hline Concept & Category \\
\hline $\begin{array}{l}\text { 1. girls' understandings } \\
\text { of covert intimidation }\end{array}$ & $\begin{array}{l}\text { Characteristics of the } \\
\text { perpetrators } \\
\text { Characteristics of the victims } \\
\text { The girls' attitudes to covert } \\
\text { intimidation }\end{array}$ \\
\hline $\begin{array}{l}\text { 2. girls' experiences of } \\
\text { covert intimidation }\end{array}$ & $\begin{array}{l}\text { Is it a problem? } \\
\text { Where it occurs } \\
\text { Close friendships }\end{array}$ \\
\hline $\begin{array}{l}\text { 3. the effect of covert } \\
\text { intimidation reported } \\
\text { by girls }\end{array}$ & $\begin{array}{l}\text { Victims' reactions } \\
\text { Reporting experiences } \\
\text { by victims }\end{array}$ \\
\hline $\begin{array}{l}\text { 4. the impact of covert } \\
\text { intimidation reported } \\
\text { by teachers }\end{array}$ & $\begin{array}{l}\text { The difficult nature of covert } \\
\text { intimidation } \\
\text { The influence of covert } \\
\text { intimidation } \\
\text { Actions taken to address } \\
\text { covert intimidation } \\
\text { The impact of school actions }\end{array}$ \\
\hline
\end{tabular}

\section{DATA ANALYSIS}

The data was analysed in recurring stages throughout each data collection phase. This meant that subsequent data gathering was used to check the initial interpretations. Using Merriam's data analysis method, the data was coded and organised into categories from which key concepts were derived (1998). Table 1 sets out the key concepts and associated categories used in data analysis. The key concept of the girls' understandings of covert intimidation was formed from the following categories: the characteristics of the perpetrators, the characteristics of the victims and the girls' attitudes to covert intimidation. 
The girls' attitudes category incorporated six subcategories based on the girls' explanations for covert intimidatory behaviours. These explanations were: preserving power and reputation, conforming to the pressure of the group, emulating other girls, gaining friends and getting rid of friends, providing a release, and acting according to natural impulses.

The category of close friendships included the subcategories of addiction, conflict, exclusive pairs, trust, betrayal in the context of close friendships, and forms of covert intimidation. The subcategory of forms of covert intimidation was split into further sub categories of: exclusion, words as weapons, insincerity, intolerance of difference, body language, threats and coercion, groups, clubs and gangs, secrets, rumours and lies, and hiding behind others.

The third key concept of the effects of covert intimidation on the girls was derived from the categories of the victims' reactions to covert intimidation and the reporting of the experiences by the victims. The final key concept, that of the impact of covert intimidation on the girls as described by teachers, was shaped by the categories of the difficult nature of covert intimidation acts, the influences on covert intimidation practices, actions taken to address covert intimidation in the school setting and the impact of school actions.

\section{FINDINGS}

\section{The girls' understandings and experiences of covert intimidation}

Girls who were perpetrators of covert intimidation were described as being bossy, conventionally pretty, smart, confident, wearing trendy clothes and having impressive material possessions. They were popular among their peers and with their teachers. They were girls who often had a strong verbal ability. This ability not only secured the approval of their teachers, who often regarded these girls as trustworthy and plausible, but it also helped to obtain useful information which could be used to hurt and humiliate others. The teacher's unwitting participation was an aspect of relational aggression that was well understood by some of the girls. As one girl reported:

They use the teacher as a shield - and then behind their backs they're - they're just really mean.

In their discussions on the subject, the girls identified the need for power as being central to the practices of covert intimidation. The girls equated power with being in control of people and they clearly saw that this was the factor that gains the top girl or popular girl the allegiance and respect of the others. One girl understood this principle very clearly when she discussed how she took her revenge for being excluded in the following way:

I would take her friends away so that she would have no friends.

These practices were understood to be essential for controlling the social order of events.
Although most of the girls in the study reported that they had experienced being a victim of covert intimidation, they observed that girls with no friends were more likely to be targets because they had no one to protect them. Other girls more likely to experience the aggression of their peers in this way included those who were different in some way and those who were quiet. In speaking of the practices, many of the girls described the dilemma they felt between the pressure to participate in actions against their peers, frequently out of fear of being isolated, and the risk that the actions would be turned on them. Two-thirds of the girls reported that they had been mean to other girls in this way.

When the girls spoke in general terms about stopping the practices of covert intimidation, they were more likely to express the view that they could stop it. When they shared information about specific situations, they spoke with a sense of powerlessness about their inability to change the course of events. It was seen to be inextricably bound up with friendships, which made it too complicated to deal with, or if it involved exclusion from a group, most of the girls appeared to have little hope that it could be stopped.

In a survey in which 22 of the 23 girls participated (one girl was absent on the day the survey was conducted), 16 reported that they had been bullied through indirect practices, while four affirmed that they had bullied another girl within the last year. Of the 22 girls, 14 reported that the bullying had been a problem for them and they discussed the pain and difficulty it had caused them, while six girls stated that it had not bothered them or that the "little bit of bullying was not a problem". Almost half (45\%) of the girls' responses to the survey question about where bullying occurred, reported that it occurred in the playground. One girl described how it can occur under a teacher's nose.

When they start bullying, they see the teacher's near ... and bully you to make sure you don't tell.

As well as occurring before and after school, covert intimidation also occurred in the classroom, particularly in the form of refusing to work with certain girls, whispering secrets and writing private notes.

During discussions with the girls, it quickly became apparent that covert intimidation was very central to the close friendships between the girls. Many of the girls spoke with great sadness about the difficulties they had experienced in their close friendships with others. Small upsets often reeled out of control and became big issues, the hidden agenda of which was to gain control of a group, or to end a close friendship due to the competition of other alternatives. As one girl said:

It wasn't really the bullies that came to me, it was me who went to the bullies because they were my friends if they didn't have other girls around them ... I couldn't (ignore them), they were my friends on their own but they would try to impress other girls.

This description also describes the ripple effect that these actions can have on others. 
The girls reported that covert intimidation came in many guises. These included words, subtle body language and actions such as forming clubs that aimed to exclude, hurt feelings, threaten, coerce, ridicule differences, break confidences or make others feel that they were invisible. One girl's experience of asking if she could play exemplifies this situation. She reported that the response took the following form:

\section{What's that strange noise? Where's it coming from? Who is that? What is that? Can I hear something?}

The girls also reported that some girls were good at hiding behind others by making them carry out their deeds. As one girl said:

Well people that do bully, they say, "if you bully this person, I'll give you this or you can be my friend."

\section{The effects and impact of covert intimidation on the girls}

The effects of covert intimidation were apparent during the research process. One girl felt too threatened to participate in the discussion group as a result of past experiences of victimisation from other girls. Several girls made personal approaches to the researcher providing names of girls they did not want to be in a discussion group with. In the discussion groups the girls described an array of responses to these acts of aggression from their peers. They ranged from responding with strong assertive responses to being frightened to challenge the aggressors for fear of further victimisation. Other responses included staying away from school, ignoring the behaviours or giving up on the situation and leaving, as well as trying to make new friends. Some had tried heart-to-heart talks with mixed success.

While some girls reported that they had had favourable results from discussing their experiences with their family, friends or teachers, many other girls had not benefited. Only a third of the girls reported that they had asked for help as a result of their relational aggression experiences, although more than half (55\%) had shared their situation with family members, friends or teachers. Most of the girls either found their mothers' or grandmothers' advice, such as to ignore the bullies, difficult to implement or feared that their parents' actions could lead to further bullying and did not want their parents to get involved.

Talking with their friends was also difficult for some of the girls, particularly those who were in and out of small friendship groups. Finding girls who could be relied on to respect confidences was of great concern. Perceived and real threats to end friendships were also cited as a good reason not to seek support from adults in the school or the school systems set up to respond to bullying. Threats persuaded one girl not to seek help from a mediator. In another incident, a class meeting to address the matter worked against the victim when the perpetrator convincingly twisted the story. Another girl related an unsatisfactory outcome when she asked a teacher to mediate.

... I got mediation but with the teacher. They said all these lies ... I didn't know what to say 'cause I hadn't done it but nobody - if they had done it - nobody would say they did.
Despite these experiences several girls stated that they felt it was important to tell teachers because they appreciated the fact that some girls bully others because they count on them not reporting incidents to teachers. Other girls reported that their problems had been resolved with teachers taking actions. More satisfactory outcomes seemed to occur for the victim when the incident was recent, occurred in close proximity to the teachers and the victim was in an obviously upset state.

The impact of covert intimidation was explored in the study through examining the teachers' understandings of covert intimidation in terms of the effects on the girls. While the teachers acknowledged that they struggled to fully understand the nature of the phenomenon, they were able to describe a range of impacts on the victims of relational aggression. Most teachers were of the view that the experiences resulted in low self-esteem and diminished self-worth. They cited incidents of girls becoming clingy and befriending younger children to be in a position of strength, and of girls who panicked and dissolved into tears when challenged by small problems. Others appeared to have little confidence and avoided new or challenging situations. Marred academic performance was observed, as was the behaviour of concentrating on academic pursuits to compensate for lack of social involvement.

The intangibility of the practices often left the teachers in a quandary as to what to do about the issue. The teachers' plight in responding to the incidents was summed up by one teacher:

You talk to them and you have not seen anything. They're very clever at ... this is why it worries me so much because bullying relies on secrecy and if you can't winkle it out, how are you going to stop it? But you know it's happening, you just do.

Teachers have difficulty gauging the frequency of the behaviours and establishing the actual version of situations, due to the ability of some of the girls to turn things around, underplay the events and make light of the actions. One teacher suggested that many of the girls find it difficult to identify clearly what is happening when the practices are directed at them, and so will focus on one small incident which frequently sounds trivial and is easily dismissed such as telling tales. Another teacher reported that because relational aggression involved relationships, the difficulties experienced were complicated and not always able to be reconciled. Another teacher expressed the belief that relational aggression will always be part of the way girls interact because it is part of human nature. These views and the fact that relational aggression by its very nature can be ignored have contributed to the situation where most schools have been slow to respond to the problem.

Despite these difficulties, most of the teachers interviewed imparted a strong sense of optimism that social education supported by school actions could make a real difference to the lives of these year 5 girls. These views were supported by taking actions in the school to address the behaviours associated with relational aggression. The actions included 
developing a support group where girls were able to problem-solve their relationship difficulties and a peer mediation system, adding explicit description of the behaviours included in the unacceptable behaviours list in the school, and post boxes for confidential reporting of incidents.

The teachers' optimism was guarded, and there was the view that unless things do change at primary school for girls there is little hope for the future prospects of many girls who experience this form of bullying from their female peers. This belief rests on the observation that practices of relational aggression increase at secondary school, leading to well entrenched patterns of behaviour that frequently extend beyond school into the workplace.

\section{DISCUSSION AND IMPLICATIONS FOR PRACTICE}

This study set out to investigate year 5 girls' experiences of covert intimidation and to explore the understandings they have about covert intimidation practices. The findings of the study suggest that covert intimidation in the school setting for this particular group of year 5 girls was a phenomenon with which they were familiar. It was part of the social fabric of their lives both in and outside the classroom, affecting their interactions with each other and their friendships. The girls clearly understood that the practices were unique to their experience as girls, with encounters involving both verbal and non-verbal aggressive behaviours that form a clandestine subculture. This culture is described by Simmons (2002) as a hidden culture in which, "bullying is epidemic, distinctive and destructive' (p.3). This study supports findings in the literature that the indirect nature of bullying by girls possibly is ignored because it takes subtle forms and there is little outward sign of harm (Sullivan, 2000).

The findings of studies carried out by Bjorkqvist, Lagerspetz and Kaukiainen (1992), Crick and Grotpeter (1995) and Simmons (2002) concur with one of the findings in this study, that relational aggression is located within girls' friendships. These friendships are the site of both highs and lows. While girls find friendships to be positive and rewarding, which results in a desire to spend every moment together, they are also fraught with difficulties as girls try to resolve their needs for connection, recognition and power. The conflict that often results is, according to Simmons (2002), deeply problematic for girls because there has long been a view that girls do not experience conflict. Historically society has ignored anger and aggression as being part of girls' behavioural repertoires, labelling girls instead as catty, deceitful and conniving. This originates from the belief that women's primary role in life is to nurture and such a role is incompatible with aggressive behaviour. Brown and Gilligan (1992) believe that it is this period of middle childhood where girls learn that the expression of strong feelings will earn disapproval from their world. In striving to achieve perfection in this dimension, girls are prevented from voicing true feelings and most particularly feelings of anger or aggression. Relational aggression allows girls to vent their anger beneath a façade of "niceness". This is confirmed by one of the participants who said:

\section{... you sort of try and hurt them on purpose and make it seem like it was a mistake...}

This study further set out to describe the effects of covert intimidation practice on year 5 girls and to consider the impact of covert intimidation practices in the school setting. The findings suggest that most girls in this study felt unable to challenge the injustices inflicted on them. Their responses of giving up, trying to ignore or getting away from the situation expressed their sense of helplessness. An explanation for this helplessness is found in a study by Osler and Vincent (2003) who reported that girls spoke about being subjected to disciplinary exclusion as a result of lashing out after suffering in silence or trying unsuccessfully to stand up to the bully. The finding that the experiences of covert intimidation resulted in girls having little confidence, avoiding new or challenging situations, underperforming academically replicates other findings. Crick et al. (1999) cite their and other researchers' findings that relational aggression was significantly associated with current and future rejection, and this increased over the school year. The subsequent lack of opportunities to experience belonging and acceptance in close relationships has been shown to be associated with feelings of loneliness, low subjective well-being and non-adjustment (Salmivalli, Kaukiainen and Lagerspetz, 1998).

Results of this study suggest that an important first step to redress this situation and help girls learn new and more appropriate ways to express their anger and resolve the conflicts arising from their relationships is to bring the issue out into the public arena. The use of the term relational aggression is a term that clearly describes what the behaviours are concerned with and supports the issue being openly discussed.

Schools can play an important role in ensuring that the experience of girls in terms of relational aggression is heard, acknowledged and considered important. Perhaps a more important implication for schools is that although females are thought to have lower prevalence rates of aggression and antisocial behaviour than males, current research suggests they are actually at greater risk of psychological maladjustment (Espelage, Mebane and Swearer, 2004). While Crick and Grotpeter's earlier research clearly showed relational aggression to be more characteristic of girls, 'in which the goal is to hurt others by damaging their reputation or their relationships' (as cited in Espelage, Mebane and Swearer, 2004, p. 16), the findings of this study support Espelage et al.'s more recent view that relational aggression plays a unique role in youth psychological and social adjustment. Furthermore, Dellasega and Adamshick (2005) contend that 'middle school is the learning laboratory for relationship skills that can last a lifetime' (p. 74).

So what can schools do? Social education programmes can raise the awareness of children from the age of five about the appropriateness of a range of social behaviours. Behaviours which comprise the practices of relational aggression can be named, listed and discussed as inappropriate in the school setting. A strong school-wide focus on prosocial behaviours as alternatives to the covert 
practices of relational aggression can have expression in school assemblies and through strategies such as "caught in the act" awards. Forums can be provided through class circles and other forms of discussion groups. Not only do these methods ensure that the girls' voices are heard, but they provide opportunities for all students to learn more appropriate ways to problem-solve difficulties in social interactions. Girls must be supported to ask for help to resolve their relationship difficulties. When teachers are proactive and respond, girls' concerns are validated and, just as with overt forms of bullying, when teachers are seen to take action, perpetrators become more considerate of their actions.

Finally, in a profession where so many teachers are women, there is the need for us to reflect on our own relationships with each other in light of our middle and secondary school experiences. Most importantly, we must discard the belief that practices of relational aggression are natural and unavoidable, and take action to support our female students to learn new ways of relating to each other through learning how to be open and honest, so they can express their emotions and formulate solutions to their conflicts.

\section{REFERENCES}

Bjorkqvist, K., Lagerspetz, K. M., \& Kaukiainen, A. (1992). Do girls manipulate and boys fight? Developmental trends in regard to direct and indirect aggression. Aggressive Behaviour, 18, 117-127.

Brown, L. M., \& Gilligan, C. (1992). Meeting at the crossroads: Women's psychology and girl's development. Cambridge: Harvard University Press.

Crick, N. R., \& Grotpeter, J. K. (1995). Relational aggression, gender, and social-psychological adjustment. Child Development, 66 (3), 710-722.

Crick, N. R., Werner, N. E., Casas, J. F., O’Brien, K. M., Nelson, D. A., Grotpeter, J. K., \& Markon, K. (1999). Childhood aggression and gender: A new look at an old problem. In D. Bernstein (Ed.) Gender and Motivation. Lincoln, Nebraska: University of Nebraska Press.

Dellasega, C., \& Adamshick, P. (2005). Evaluation of a program designed to reduce relational aggression in middle school girls. Journal of School Violence 4(3), 63-76.

Department of Education, \& New Zealand Police, (1987). Keeping ourselves safe: Knowing what to do (J1-3/Std. 1). Wellington: Government Print.

Department of Education, \& New Zealand Police (1987). Keeping ourselves safe: Knowing what to do (Senior Primary, Form 1-2). Wellington: Government Print.

Espelage, D. L., \& Swearer, S. M. (2004). Bullying in American schools. A social-ecological perspective on prevention and intervention. Mahwah, New Jersey: Lawrence Erlbaum Associates, Publishers.

Espelage, D. L., Mebane, S. E., \& Swearer, S. M. (2004). Gender differences in bullying: Moving beyond mean level differences. In D. L. Espelage and S. M. Swearer (Eds.).
Bullying in American schools. A social-ecological perspective on prevention and intervention. Mahwah, New Jersey: Lawrence Erlbaum Associates, Publishers.

Galen, B. R., \& Underwood, M. K. (1997). A developmental investigation of social aggression among children. Developmental Psychology, 33, 589-600.

Geffner, R. A., Loring, M., \& Young, C. (Eds.) (2001). Bullying behaviour: Current issues, research, and interventions. New York: The Haworth Maltreatment \& Trauma Press. Co-published simultaneously as the Journal of Emotional Abuse, 2(2/3), 2001.

Merriam, S. B. (1998). Qualitative research and case study application in education. San Francisco: Jossey-Bass.

Moore, D., Adair, V., Lysaght, K., \& Kruiswijk, J. (1997). Eliminating violence from schools evaluation project: Final report. Auckland: Auckland Uniservices Ltd, University of Auckland.

Murrow, K., Kalafatelis, M., Fryer, M., Ryan, N., \& Dowden, A., BRC Marketing and Social Research (2004). An evaluation of three programmes in the innovations funding pool. $\mathrm{Coo}$ schools. Report to the Ministry of Education. Wellington: Ministry of Education Research Division.

New Zealand Police, Crime Prevention Unit (2000). Kia Kaha [kit]: A bully free zone, middle primary, years 4-6. Wellington: Author.

New Zealand Police (1992). Kia kaha [kit]: A resource kit about bullying for students, teachers and parents for Standard 3-Form 4. Wellington: Author.

New Zealand Police: Youth Education Service (2002). Kia kaha for secondary school [kit]: Our place. Wellington: Author.

Olweus, D. (1993). Bullying at school: What we know and what we can do about it. Oxford: Blackwell Publishers.

Osler, A., \& Vincent, K. (2003). Girls and exclusion: Rethinking the agenda. London: Routledge Falmer.

Peace Foundation Aotearoa/New Zealand (1992). Cool schools peer mediation programme. Auckland: Aotearoa/New Zealand Foundation for Peace Studies Inc.

Robinson, G., \& Maines, B. (1997). Crying for help: The no blame approach to bullying. Bristol: Lame Duck Publishing.

Salmivalli, C., Kaukiainen, A., \& Lagerspetz, K. (1998). Aggression in the social relations of school-aged girls and boys. In P. T. Slee \& K. Rigby (eds.), Children's peer relations. London: Routledge.

Simmons, R. (2002). Odd girl out: The hidden culture of aggression in girls. New York: Harcourt.

Special Education Service, (1993). Eliminating violence: Managing anger. A school and community violence prevention programme. Papatoetoe: Author.

Stanley, L., \& Arora, C. M. J. (1998). Social exclusion amongst adolescent girls: Their self-esteem and coping strategies. Educational Psychology in Practice, 14, 94-100. 
Sullivan, K. (1998). An evaluation of Kia kaha, the New Zealand Police's resource kit about bullying for students, teachers and parents. Report for the New Zealand Police. Wellington: Author.

Sullivan, K. (2000). The anti-bullying handbook. Auckland: Oxford University Press.

\section{AUTHOR PROFILES}

Jennifer Browne is a psychologist working in the school focus team in Auckland. Previously she has worked as an RTLB, a Guidance and Learning Unit teacher and has had experience both as a classroom teacher and special class teacher. This article describes the research carried out to complete a Masters of Educational Psychology.

Janis Carroll-Lind is a senior lecturer in inclusive education at Massey University College of Education. She also teaches an on-line paper on the role of the mentor teacher. Prior to her current position, Janis has been an early childhood and primary school teacher, an adjustment class teacher for children with behaviour difficulties and a Resource Teacher Special Needs.

\section{Email}

jennifer.browne@minedu.govt.nz J.Carroll-Lind@minedu.govt.nz
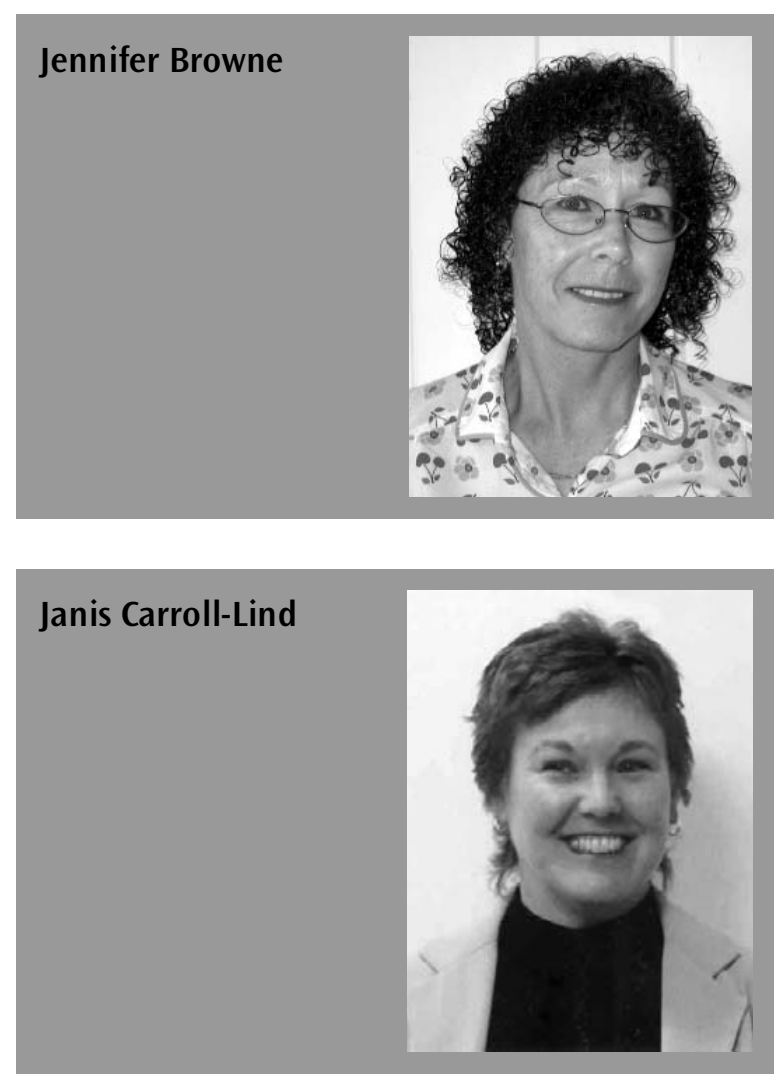


\section{APPENDIX 1}

\section{Survey Questionnaire}

\section{SURVEY ON BULLYING AMONG GIRLS}

I am interested to find out if girls bully other girls secretly in this school. I want to find out if there are ways that some girls make other girls unhappy by being mean to them. This kind of bullying is not the pushing and hitting kind of bullying. It is a kind of bullying where girls say and do things to stop other girls joining in games or being part of a group of friends. Some girls might whisper secrets to make a person feel bad, or they might laugh at them or say things about how they look. Sometimes girls get other girls to do these mean things by telling them they won't be their friend if they don't. These are just some of the things that can happen but you may know of others.

This is confidential so do not put your name on this paper. No one will know what you write and the things you write will not affect you or anyone in your class. Spelling is not important for this and if you need help and don't understand, put up your hand and I will help you.

Please answer the questions as honestly as you can.

If you don't want to answer a question you have the right to leave it.

Age

$$
\text { years and }
$$

months

Ethnicity (tick the ethnic groups you belong to)

$\begin{array}{ll}\square \text { Chinese } & \square \text { Korean } \\ \square \text { Indian } & \square \text { Samoan } \\ \square \text { Māori } & \square \text { Pakeha } \\ \square \text { Cook Island } & \square \text { Other }\end{array}$

\section{(Circle one)}

1. Has bullying between girls been a problem for you at school? Yes No

2. Have you been bullied by girls at school this year or last year? Yes No

3. Have you bullied another girl this year or last year Yes No

4. If Yes how often have you been bullied by girls? (tick one)

$\begin{array}{ll}\square \text { only once } & \square \text { once a month } \\ \square \text { once a week } & \square \text { every day } \\ \square \text { more than once a day } & \end{array}$

5. When does the bullying by girls happen? (You can tick more than one box). $\square$ on the way to school $\square$ before school $\square$ at playtime or lunchtime $\square$ in the classroom $\square$ after school

6. Which girls get bullied by girls the most? (Circle the ones you think). quiet girls girls who are different girls who argue lots bossy girls naughty girls popular girls girls with no friends

7. Which girls bully other girls the most? (Circle the ones you think). girls who are different girls who argue lots naughty girls bossy girls popular girls girls with no friends girls who are popular with teachers
(If you haven't been bullied by girls go to No. 13)

8. Did you tell anyone when you were bullied by other girls? Yes No

9. Did you ask for help? Yes No

10. Who did you tell?

11. What happened when you told someone?

12. How did you feel when the bullying was happening?

13. What kinds of things do girls do when they bully other girls?

14. Why do you think some girls pick on other girls?

15. What could girls do to stop the bullying. Write down any good ideas you have tried or can think of.

16. Do you think you can do something to stop other girls bullying girls? Yes No

17. Do the teachers ever see this bullying? Yes No If Yes, what did they do?

18. Does your school do anything when girls bully other girls? If Yes, what happens?

19. Does this stop the bullying? Yes No

20. What do you think can help stop this problem of girls bullying other girls?

Thank you very much for thinking so carefully about this. 


\section{APPENDIX 2}

Written Worksheet

Worksheet: about girls bullying other girls in this school.

This bullying is the kind of bullying where girls say and do things to stop other girls joining in games or being part of a group of friends. Some girls might whisper secrets to make a person feel bad, or they might laugh at them or say things about how they look. Sometimes girls get other girls to do these mean things by telling them they won't be their friend if they don't. These are just some of the things that can happen but you may know of others.

Write about a bad time when a girl or a group of girls were mean to you in this way.

You may want to write about a time you were mean in this way to another girl.

If this hasn't happened to you or you haven't been mean to someone else write about a time when you saw it happen to someone else.

How did it start?

If it happened to you (or you saw it) what did they do?

(If you are writing about something you did, write what you did)

What did they say? (If you are writing about something you did, write what you said.)

What did you think?

How did you feel?

What happened at the end?

If it happened to you did you ask for help? Yes No (circle one)

If you answered YES, who did you ask and what happened?

If anything changed when you asked for help, were things better or worse? In what way?

If you have anything else you want to write about this problem or girls being mean to other girls write it here.

Do you think YOU can do something to stop other girls bullying girls?

Yes Sometimes No (circle one)

What kinds of things can you do?

Sometimes girls who have been bullied have also been mean in this way to other girls?

Is this true for you? Yes Sometimes No (circle one)

Thank you for thinking so hard about this.

\section{APPENDIX 3}

Interview Schedule: Students

Semi-structured Interview Schedule for Students Focus Groups

Definition of Covert Intimidation: Sometimes girls say things or do things to stop other girls from joining into a group or an activity. Sometimes the things they say and do stop other girls being friends with each other or they leave some girls without friends. This means these girls feel sad and lonely. Often girls do and say these things so that only the girls involved see or hear. Adults often don't know that it is going on.

In this discussion I am hoping you can tell me about the kinds of things girls do when they are mean to girls in this way. I am interested to know what happens when they do this and why you think it happens. When you are talking about things that girls do it is important that we use $X$ instead of saying people's names.

1. Do you think this behaviour is a problem? How big a problem is it for you?

2. What do you see girls do and what do you hear them say when they bully others in this way.

- Can anyone tell me about the things they have seen or heard? What do girls do and what do they say?

- Some girls hit and kick others - is this part of secret bullying?

- Is this being mean to other girls mostly with friends or does it happen between girls who aren't friends.

3. Without using girls names which girls do this kind of thing most often?

- Is it the girls who the teachers think are good or is it the girls who get into trouble a bit from the teachers.

- Is it one person by themselves or is it often more than one person?

- Can it be a group idea?

- Is the bully more often a popular person, an unpopular person, a naughty person or a bossy person or another type of person?

4. Without using girls names which girls are bullied like this most often? Girls who are:

quiet different

those who have no friends new girls

those who argue a lot those who are quite naughty those who are bossy those who are popular

5. If you have been bullied by other girls in the way we have been discussing can anyone tell me:

- What happened to you?

- How did you feel when it was happening?

- What did you think and say to yourself?

- Did it change how you felt about school, your class, yourself?

- Do you think it changed how you act now in the playground or in the classroom?

- Have you ever tried to stop this mean behaviour? What sort of things did you do? Did they work? What didn't work?

- Does anyone want to talk about something they did to someone else? 
- How can you tell the difference between a girl joking and playing about in a friendly way and in a mean way? What do you hear? What do you see?

- Can girls who have been bullied go on and bully others?

6. What should be done about girls hurting other girls in this way?

- What have you done when you've had this problem? Did you ask anyone for help?

- Did anyone do or say anything to stop this mean behaviour?

- What do you think should happen to girls who are mean to others?

- What should people do to help the person who is the victim of these behaviours?

- What happens when you stick up to the bully? What things do you say and do?

7. Why are girls mean to each other in this way?

- Have you any idea why some girls pick on other girls?

- Why do some girls get bullied and other girls don't?

- Do you think that this kind of bullying can be stopped? How? By whom?

- Do you have any ideas how to stop girls being mean to each other in this way?

- If we could have a perfect world how would you like things to be between girls and how would you like things to be for you?

\section{APPENDIX 4}

\section{Interview Schedule: Teachers}

\section{Semi-structured Interview Schedule for Teachers}

(Participants have the right to ask for the audio tape to be turned off at any time during the interview)

Definition of Covert Intimidation: practices which aim towards socially isolating others through intentional exclusion from groups. It involves behaviours that harm others through damage (or the threat of damage) to relationships or feelings of acceptance, friendship or group inclusion. Often these practices are observable by the victim and by the victim's and perpetrator's peers, but can go unobserved by adults.

This interview seeks to gain insight into your perspectives of the phenomenon of covert intimidation among girls. I am particularly interested in your views as to why you think these practices occur and what you consider the consequences and implications to be.

1. Background questions

- How long have you taught in this school?

- What type of teaching position do you currently hold?

- What particular interest areas and areas of responsibility do you hold within the school community?

2. Awareness and knowledge of covert intimidation amongst nine-year-old girls.

- Do you think bullying of this kind occurs among nine-year-old girls?
- What sort of behaviours have you seen?

- What sort of behaviours have been reported to you?

- Are there any particular characteristics of girls who bully other girls?

- Do girls bully other girls as individuals or in groups?

- What status do bullies of girls have amongst their peers?

- Are there clear lines between bullies and victims or can bullies be victims and victims be bullies?

- Are there any particular characteristics of girls who are victims of bullying by other girls?

- Some girls said that some girls who are popular with the teachers are often the ones who bully. Have you observed this? How could you explain it?

3. Why does it happen?

- Ideas and views as to why covert intimidation practices occurs between girls.

- What factors contribute to some girls bullying more than others, some being bullied more than others and some girls not being bullied by girls at all and some girls hardly being aware of bullying occurring?

4. Consequences and Implications

- I want to read you a range of responses from the girls who have been bullied. Do you have any thoughts about the implications of these responses?

- Observations of changes in the behaviour of girls who have been bullied by other girls. Are the changes immediate and short or medium term?

- In what areas have the changes been observed? (For example confidence, attendance, learning performance, motivation, task avoidance, friendships).

- Thoughts as to the long term implications of girls who experience covert intimidation practices and those who perpetrate the practices.

5. Teachers and school response to covert intimidation practices

- Have you experienced girls reporting this behaviour to you?

- If so have you taken any action?

- What kinds of action have you taken?

- Were those actions effective? In what way?

- Does the school have procedures in place to deal with covert intimidation practices among girls?

- If so what procedures are there?

- Are they able to be easily accessed by the students, do you think?

- Do you think that the girls think they can easily access them?

- In what ways would you say these procedures are effective in addressing this behaviour?

- Do you think girls feel safe at this school? If yes, why?

- If no, what do you think needs to happen at this school to ensure their feelings of safety?

- In your view do you think it is possible to educate and socialise girls to interact without engaging in covert intimidation practices?

- Do you have any other comments you would like to add? 